\title{
An Efficient and Facile Synthesis of 1-Alkyl-3,5-diaminobenzenes
}

\author{
Sung Hoon Kim, Eun-Young Heo, and Yong-Bae Kim
}

\author{
Department of Chemistry, Konktk University, Seoul 143-701, Korea \\ Received April 19, 2003
}

Key Words : 1-Alkyl-3.5-diaminobenzenes. Di-t-butyl malonate. 3.5-Dinitrobenzoyl chloride. Poly imides. Alignment film

The diaminobenzene derivatives have been treated as precursors of polyimides which are widely used in various fields such as protective materials. ${ }^{3}$ insulating materials. ${ }^{-}$and immobilizing films ${ }^{3}$ for diagnostic assays and bioreactors. and especially alignment films $\mathrm{s}^{4}$ in the liquid crystal display (LCD). For most of the liquid cry stal display (LCD) devices. liquid crystal molecules are aligned with a certain inclination angle to the rubbed polyimide surface. In order to develop VA mode LCD. it is very important to align the liquid crystal molecules perfectly vertical to the matrix. If the polyimide matrix has vertically aligned tails standing at a regular distance. the applied liquid crystal molecules can be aligned vertical to the surface due to the interaction between the tail and liquid crystal molecules. ${ }^{5}$ However most of the diaminobenzene derivatives are within the limit of 1-substituted 2.4diaminobenzene derivatives because of the limitations in the synthetic methods. ${ }^{6}$ It is impossible for the polyimides from 1-substituted 2.4-diaminobenzenes to align the liquid crystal molecules vertical to the surface due to the declined tails. On the other hands. polyimides prepared from 1-alkyl-3.5diaminobenzenes are regarded to have the capability of aligning liquid crystal molecules vertical to the surface with enough chemical stability compared to the other functional group. Also it is very important to have long alkyl chain for efficient vertical alignment of liquid cry stal molecules. ${ }^{4}$

It seems to be very difficult to introduce long chain alkyl groups at 1 position. Most of the reported 3.5-diaminobenzenes have substituents such as allylic. halogen. short chain alkyl. heterocyclic. hydroxyll alkyl ether. formyl. ester. and amides. ${ }^{4.7}$ The synthetic method for 1-alkyl-3,5-diaminobenzenes have not been reported in the literature to our knowledge except for only one example. 1-pentyl-3,5-diaminobenzene prepared from olivetol. ${ }^{3}$ However this type of method has limitations in introducing various length of alkyl chain because of commercial availability of the starting material and multiple low yield steps.

As a preliminary work in developing polyimides for VA mode LCD. we developed a very efficient sinthetic method for the preparation of 1-alkț1-3.5-diaminobenzene 8 with various length of alkỵl chains from commercially available di-t-butyl malonate and 3.5-dinitrobenzoyl chloride as starting material (Scheme 1,2).

First. intermediate ketones 3 were synthesized from the reaction of 3.5 -dinitrobenzoyl chloride with di-t-butyl $n$ alkỵlnalonates prepared fron di-i-butỵl malonate and $n$ alkỵl bromides with various chain length in good yields. Then. the carbobutoxy moieties of the ketones 3 were removed with the aid of catalytic amount of $p$-toluenesulfonic acid to give almost quantitatively 1-acylated 3.5-dinitrobenzenes 5 in one pot reaction (Scheme 1). The use of di-i-butyl $n$ alkyinalonate is one of the key points in our synthetic method. We were able to introduce alkyl chain of various length at this stage and prepare 3-(3.5-dinitrophenyl)-2alky1-3-oxopropionic acids 4 efficiently at room temperature. Further decarboxylations were carried out easily by heating. When diethyl $n$-alkỵlmalonate was used instead of di-t-butyl ester. reverse process occurred in the hydrolysis step as expected ${ }^{\text {sa }}$ Several synthetic methods to circumvent this difficulty were reported in literatures. ${ }^{s}$ Although general reagents for reduction of nitrophenone compounds reported in literatures are borohỵdrides such as $\mathrm{NaBH}_{4}$ and $\mathrm{KBH}_{4}{ }^{\circ}$ sodium borohydride reduction of 1-acylated 3.5-dinitrobenzenes 5 resulted in poor yield of benzyl alcohol 6 . We found that triethylsilane with boron trifluoride etherate was

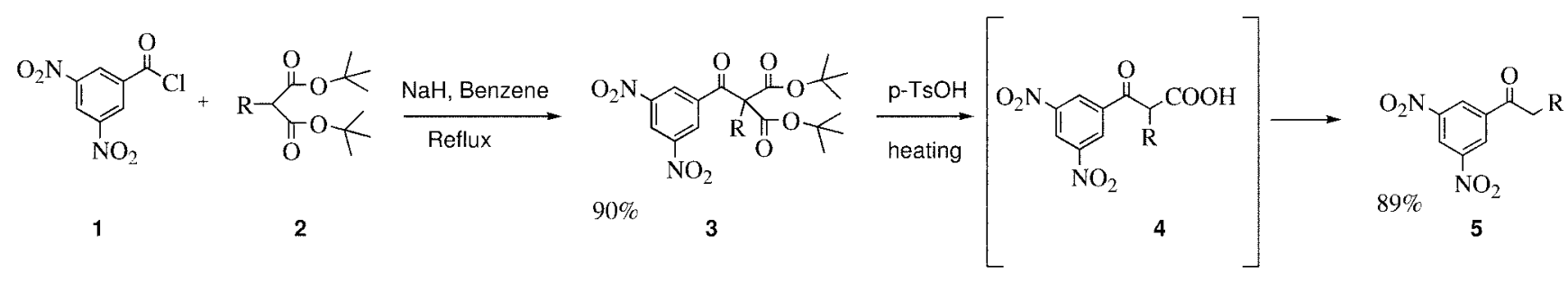

$\mathrm{R}=\mathrm{C}_{\mathrm{n}} \mathrm{H}_{2 \mathrm{n}+\mathrm{l}} \mathrm{n}=10,12,14,16$

Scheme 1. Synthesis of ketones 5 from di-t-butyl malonates 2.

Comesponding author. E-mail: shkintatklucc.konkuk.ac.kr 
<smiles>CCC(=O)c1cc(C#N)cc([N+](=O)[O-])c1</smiles>

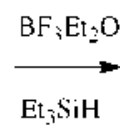

5<smiles>[R]CC(O)c1cc([N+](=O)[O-])cc([N+](=O)[O-])c1</smiles>

6

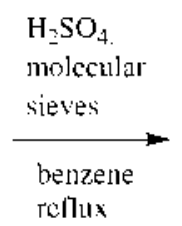<smiles>[R]C=Cc1cc([N+](=O)[O-])cc([N+](=O)[O-])c1</smiles>

7

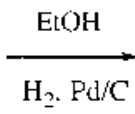

$89 \%$<smiles>[R]CCc1cc(N)cc([Hg])c1</smiles>

8

$$
\mathrm{R}=\mathrm{C}_{n 11} \mathrm{H}_{2 n+1} \quad \mathrm{n}=10.12 .14 .16
$$

Scheme 2. Sinthesis of 1-alkrl-3,5-diaminobenzene 8 .

very efficient to prepare benzylic alcohol cleanly without spoilage of dinitro group in dinitrobenzenes. ${ }^{11}$ The ultimate product, 1-alkyl-3,5-diaminobenzenes 8 , were synthesized exclusively by catalytic hydrogenation of 1-alkenyl-3,5dinitrobenzenes 7 , which is prepared from the dehydration of 1-(1-hydroxyalhyl)-3,5-dunitrobenzenes 6 with catalytic amount of sulfuric acid (Scheme 2). Typical synthetic procedures for the products are described in the references. ${ }^{11}$

In conclusion. we have developed a facile and efficient synthetic method of 1-alkyl-3.5-dianinobenzenes with various length of alkyl chains. which are regarded as key starting materials for polyimides. We are now studying the utilization of $\mathrm{I}$-alkyl-3.5-diaminobenzenes to polyinides using dianhydrides such as cis-1.2.3.4-cyclopentanetetracarboxylic dianhydride (CPDA) and 1,2,4.5-benzenetetracarboxylic dianhydrides (PMDA) for VA mode LCD.

Acknowledgments. This work was performed Advanced Backbone IT teclunology development project supported by Ministry of Information \& Communication in Republic of Korea.

\section{References and Notes}

1. (a) Eindrey A. L. LS Pat. Appl LS 3179630, 1965. (b) Bruma. M.: Popescu. P.: Ionita. M. Afateriale Plastic 1982, 19, 237.

2. (a) Mesaki, M: Tatematsu, Y.: Sugiura. M.PCT Int Appl. WO99: 41757. (b) Pfeifer. J.: Duthaler. R. Em: Pat .Appl. EP 252883. 1988

3. Pegg. R. K.: Saunders. M. S. US Pat Appt. US $5+36147.1995$.

4. Nihira. T. Eur: Pat Appl. EP 0679633. 1995.

5. Demus, D: Goodby: I.: Gray, G. W. In Handbook of Liquid Coystals, Vol. 2A: Wiley-VCH: 1998; pp 200-201.

6. (a) Wessely. F.: Eibl. H.: Friendrich. G. Monatsh 1952. 83.24. (b) Obera. H.: Onodera. J.: Matukuma. A.: Yoshida. K. Ger: Pat. Appl. DE 2445336. 1975. (c) Scholl. H. J. Ger. Pat. Appl. DE 3105362. 1982. (d) Ben Taleb. A.; Tenner. G. J Mol Cotalvsis 1994 91. 149L. (e) Kelly: T. R.: Cavero, M. Org Lett 2002. 4. 2633.

7. (a) Mever M.: Cassebaum. H. Ger.(East) Pat .Appl. DD 228807. 1985. (b) Tsukase. M.: Uchida. O.: Ookawa. A.Jpm. Pat .Appl. JP 08109157. 1996. (c) Gowda. D. C.: Gowda. S. Indian J. (them.. Section B 2000. 39B. 709. (d) Ishida. H.: Qi. Z.: Sokabe. M: Donowaki. K.: Inoue. Y. J. Org. Chent 2001, 66, 2978.

8. (a) Bowman. R. E. J. Chem Soc. 1950, 322. (b) Fonken, G. S: Johnson, W. S. J. Am. Chem. Soc. 1952. 7t, 831 . (c) Puterbaugh,
W. H.: Swamer. F. W.: Hauser. C. R. J. Am. Chem. Soc. 1952. 74. 3438. (d) Bowman. R. E. J. Chent. Soc. 1950. 325.

9. (a) Yakabe. S. Camadiam J. Chem. 1998. 76. 1916. (b) Zhao. D.: Quo, Q: Cheng. M:- Zhang, Y: Gan. L.: Wang. M. Zhonggro Fowu Huaxue Zazhi 2000, 10, 262. (c) Bae, J. W.: Lee, S. H.: Jung. Y. J.: Maing Yoon. C. O.: Yoon, C. M. Tetrahledron Lett. 2001. 42. 2137.

10. Yao. T. S.: Wu. Y. S. Gaodeng Anexiao Huaxue Auebao 2002. 23. 68.

11. Typical reaction procedures are as follows: (a) Preapration of di-tbutyl 2-(3.5-dinitrobenzoyl)-2-dodecylmalonate 3. To a mixture of alky/malonate $2(1.730 \mathrm{~g} .5 \mathrm{mmol})$ and sodium hydride $(0.39 \mathrm{~g}$. $7.5 \mathrm{mmol}$ ). which was refluxed for $2 \mathrm{hr}$ in the misture of betzene $(20 \mathrm{~mL})$ and THF $(10 \mathrm{~mL})$. was added 3.5 -dinitrobenzoyl chloride 1 ( $1.153 \mathrm{~g} .5 \mathrm{mmol})$ at once. The misture was reflused for $1 \mathrm{minl}$. cooled to rt. filtered over Celite and washed with hexane. The organic laver was dried over anhydrous magnesium sulfate. evaporated in vacuo. chromatographed on silica gel to give compound 3. (2.600 g. 90\%). ${ }^{1} \mathrm{H} \mathrm{NMR}(\mathrm{CDCl}, 3): \delta 9.2$ (dd. lH). 9.0 (q. $2 \mathrm{H}$ ). 2.3 (t. $2 \mathrm{H}$ ). 1.5 (m. $19 \mathrm{H}$ ). $1.4-1.3$ (m. $20 \mathrm{H}$ ). 0.9 (t. $3 \mathrm{H}$ ). (b) Preparation of 3.5-dinitro-1-tetradecyloyl-benzene 5. To the mixture of $3(0.65 \mathrm{~g}, 1.12 \mathrm{mmol})$ and catalytic amount of $p$ toluenesulfonic acid was added 3 drops of trifluoroacetic acid. heated in reduced pressure and chromatographed on silica gel to give product $5\left(0.377 \mathrm{~g} .89^{\circ} \circ\right)$. ' $\mathrm{H}$ NMR $\left(400 \mathrm{MHz} . \mathrm{CDCl}_{3}\right): \delta 9.3$ (dd. $1 \mathrm{H}) 9.2$ (q. $2 \mathrm{H}) .2 .9$ (t. $2 \mathrm{H}$ ). 1.9 (m. $2 \mathrm{H}$ ). 1.2-1.4 (m. 20H). 0.8-0.9 (m. $3 \mathrm{H}$ ). (c) Preparation of 1-(3.5-dinitrophenyl)-tetradecanol 6. To the solution $5(0.378 \mathrm{~g} .1 \mathrm{mmol})$ in dichloromethane $(5 \mathrm{~mL}$ ) was added triethysilane ( $1 \mathrm{~mL} .6 .3 \mathrm{mmol}$ ) and boron trifluoride etherate $(2 \mathrm{~mL} .15 .8 \mathrm{mmol}$ ) at room temperature, stirred for $3 \mathrm{hr}$ and then extracted with ether. The organic layer was dried over anhydrous magnesium sulfate. evaporated in vacto and chromatographed on silica gel to give the product $6(0.320 \mathrm{~g}$. $84^{\circ}$ o). ${ }^{1} \mathrm{H}$ NMR (400 MHz. CDCl $\left.1_{3}\right): \delta 9.0(\mathrm{~d}, 1 \mathrm{H}), 8.5(\mathrm{q} .2 \mathrm{H}), 4.9$ (t. $1 \mathrm{H}), 3.5(\mathrm{~s}, 1 \mathrm{H}), 1.8(\mathrm{~m} .2 \mathrm{H}), 1.2-1.5(\mathrm{~m} .22 \mathrm{H}), 0.9(\mathrm{~m} .3 \mathrm{H})$. (d) Preparation of 1.3-dinitro-5-tetradec-1-enylbenzene 7. The solution of $6(0.760 \mathrm{~g} .2 .0 \mathrm{mmol})$ with catalytic amount of sulfuric acid and molecular sieves in betizene was refluxed for $4 \mathrm{hr}$ and then extracted with ether. washed with $5^{\circ}$. i sodium bicarbonlate and water. The organic layer was dried over anhydrous magnesium sulfate, evaporated in vacuo and chromatographed on silica gel to give the product $7\left(0.623 \mathrm{~g} .86^{\circ} \%\right)$. ${ }^{1} \mathrm{H}$ NMR $(400 \mathrm{MHz}, \mathrm{CDCl})$ ): $\delta$ 8.9 (p. $1 \mathrm{H}$ ). 8.5 (p. $2 \mathrm{H}$ ). 6.5 (m. $2 \mathrm{H}$ ). 2.3 (m. $2 \mathrm{H}$ ). 1.5 (m. $2 \mathrm{H}$ ). 1.3 (m. 18H). 0.9 (t. $3 \mathrm{H}$ ). (e) Preparation of 1.3-diamino-5-tetradecylbenzene 8 : The solution of $7(0.362 \mathrm{~g} .1 \mathrm{mmol})$ it ethanol was reduced with catalytic amount of Pd:C(10\%) under $\mathrm{H}_{2}$ stream of 40 psi. The PJC was filtered off. evaporated in vacuo and chromatographed on silica gel to give product $8\left(0.324 \mathrm{~g} .89^{\circ} \mathrm{o}\right)$. ${ }^{1} \mathrm{H}$ NMR (400 MHz. CDCl$): \delta 6.0$ (s. $2 \mathrm{H}$ ). 5.9 (s. IH). 3.5 (s. $4 \mathrm{H}) .2 .4(\mathrm{~m} .2 \mathrm{H}) .1 .5(\mathrm{~m} .2 \mathrm{H}) .1 .3(\mathrm{~m} .22 \mathrm{H}) .0 .9(\mathrm{t} .3 \mathrm{H})$. 